\title{
LAS CÉLULAS MAMARIAS EN PROCESO DE DIFERENCIACIÓN DISMINUYEN SU VOLUMEN CITOPLASMÁTICO Y NUCLEAR
}

\author{
Ricardo Cornejo U. ${ }^{1}$ Ph.D. \\ ${ }^{1}$ Departamento de Ciencias Básicas, Facultad de Medicina, Universidad de La Frontera, Temuco.
}

\begin{abstract}
RESUMEN
Las modificaciones experimentadas en el proceso biológico de diferenciación celular determinan cambios complejos y fundamentales en la ultraestructura, la bioquímica y la fisiología celular que pueden ser apreciadas claramente utilizando técnicas morfométricas, las cuales traducidas en información cuantitativa permiten evidenciar los cambios que conlleva este mecanismo. Células normales de epitelio mamario de rata, mantenidas en cultivo, estimuladas a proliferar con el factor de crecimiento epidérmico, originan el grupo celular HC11 GM. Estas células normales y proliferantes son inducidas a diferenciarse mediante inducciones de hormonas lactogénicas: dexametasona, prolactina e insulina, determinándose la generación de un tipo celular diferenciado: HC11 IM. Estudiamos a nivel de microscopía electrónica estos tipos celulares, procurando datos morfométricos discriminantes a lo largo de la diferenciación, diagnosticando las fracciones volumétricas de componentes celulares, determinando así mismo la variación en el área de las células involucradas, precisando de este modo, nuevos marcadores en el padrón de modificación que caracteriza este proceso.
\end{abstract}

\section{PALABRAS CLAVES: Diferenciación celular, morfometría, glándula mamaria}

\section{SUMMARY}

The changes suffered during the biological process on cell differentiation posses complex and fundamental changes in cell ultrastructure, biochemistry and physiology that can clearly be observed using morphometric techniques, wich, once translated on quantitative information, allow to evince the transformations sustained by this mechanism. Cultured normal rat epithelial breast cells, stimulated to proliferate by epidermic growth factor, give origen to $\mathrm{HC} 11 \mathrm{GM}$ cell group. These normal-proliferative cells are induced to differentiate by lactogenic hormones, like dexamethasone, prolactine and insuline, generating a differenciated cellular type: HC11 IM. Discriminating morphometric data of these cell types along of the differentiation process was obtained by electronic microscopy studies showing also variation on cell size though demostrating new markers on the modification pattern that characterizes this process.

\section{KEY WORDS: Cellular differentiation, morphometry, mammary glands}

\section{INTRODUCCIÓN}

Las células HC11 constituyen una línea de epitelio mamario normal, mantenida en cultivo y derivada del linaje COMMA 1D obtenida de glándula mamaria de ratas $B A L B / c$ en mitad de la preñez, las que se disponen en contacto estrecho y forman un epitelio cúbico en monocapa. Estas 
células retienen características de la diferenciación normal de la glándula y producen $\beta$ caseína, la principal proteína de la leche (1).

Estas células son inducidas al proceso de diferenciación por las estimulaciones de prolactina, hormona que modula la transcripción de genes para $\beta$ caseína y promueve acúmulo de este RNA mensajero en el citoplasma (2). Del mismo modo, insulina y su funcionalidad anabólica estimula la síntesis proteica de estas células epiteliales (3), finalmente dexametasona, glicocorticoide que induce la diferenciación terminal de estas células mamarias actuando sinergicamente con prolactina en la expresión del gen de $\beta$ caseína (4).

Las células mamarias reciben también estimulaciones del factor de crecimiento epidérmico (EGF), agente mitogénico que se une con un receptor tirosina quinasa a nivel de la membrana plasmática fosforilando una serie de proteínas citoplasmáticas, etapa fundamental en el desarrollo de la respuesta mitogénica (5).

A este respecto fue descrito que en las células HC11 la activación de los receptores para EGF es un paso esencial tanto para el crecimiento celular como para adquirir competencia en la respuesta a los estímulos de hormonas lactogénicas (6).

En este mismo contexto, ya fue también demostrado que las células HC11 sintetizan y secretan proteínas como las glicoproteínas laminina y tenascina tanto en ausencia como presencia del EGF (7).

\section{MATERIAL Y MÉTODO}

Microscopia electrónica de transmisión. Al pellet que contenía las células HC11 GM, y HC11 IM se le adicionó solución de glutaraldehído $2 \%$, en tampón fosfato $0,15 \mathrm{M}, \mathrm{pH} 7,2$, y se mantuvo a temperatura ambiente por 2 horas. Posteriormente, fue sometido a un lavado en solución de $6 \mathrm{~g}$ de $\mathrm{NaCl}$ y $73 \mathrm{~g}$ de sacarosa, disueltos en 1 litro de agua destilada. La post-fijación se realizó en solución de tetróxido de osmio $1 \%$, disuelto en la solución de lavado antes descrita durante una hora a $40^{\circ} \mathrm{C}$ y acetato de uranilo $0,5 \%$, por 18 horas. Luego de lavado el material fue deshidratado en concentraciones crecientes de acetona (30 a $100 \%$ ) e incluido en Araldita 6005 . Se obtuvieron cortes ultrafinos de aproximadamente $70 \mathrm{~nm}$ de grosor los que fueron tratados con acetato de uranilo $2 \%$, durante 40 minutos y citrato de plomo $0,5 \%$, por 10 minutos. Las muestras fueron estudiadas y fotografiadas en un microscopio electrónico Phillips EM 400.
Método estereológico. A partir de los bloques para microscopia electrónica, fueron obtenidos cortes ultrafinos, en los cuales se micrografiaron cada uno de los tipos celulares, con un aumento de 23.000 X. Para la evaluación de las fracciones volumétricas de los diferentes componentes celulares, fue sobrepuesto un retículo de puntos, en las micrografías electrónicas y se procedió al conteo diferencial de los puntos que incidían sobre los perfiles de los componentes celulares, calculándose la fracción volumétrica que un determinado componente ocupa, mediante la siguiente ecuación:

$$
P=\frac{\left(1-P_{p}\right)}{\left(e^{2}-P_{p}\right)}
$$

Donde:

$\mathrm{P}=$ número total de puntos incidentes sobre la unidad de volumen.

$P_{p}=$ estimativa previa de la fracción volumétrica del componente en estudio.

$\mathrm{e}=$ error patrón relativo que se desea tener asociado a la fracción volumétrica.

Para el cálculo del área celular fue utilizado un Planímetro Polar, Ott Kempte, Bayern, Germany.

\section{RESULTADOS}

A partir de las micrografías electrónicas obtenidas de los tipos celulares tanto normales como diferenciados (Figuras 1 y 2), se realizaron sobre ellas los análisis morfométricos correspondientes.

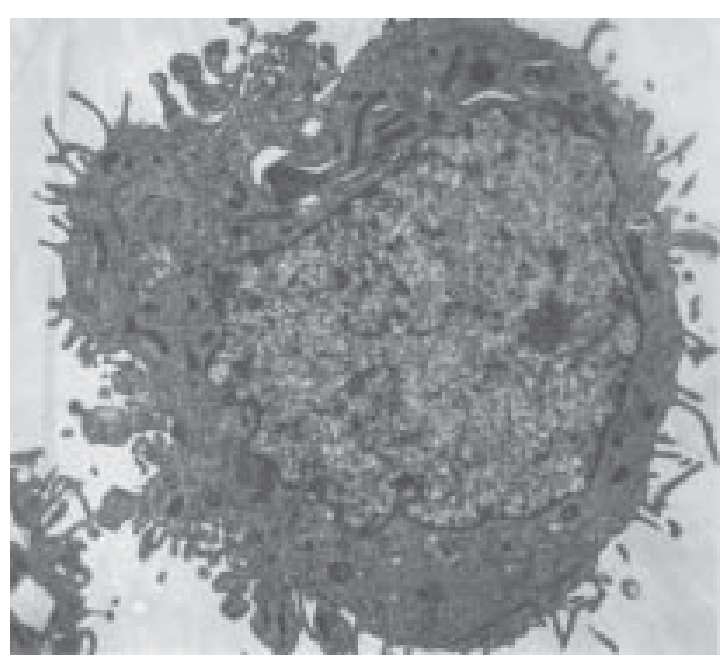

Figura 1. Micrografía electrónica de célula epitelial mamaria normal - proliferante HC11 GM 9.000X. 


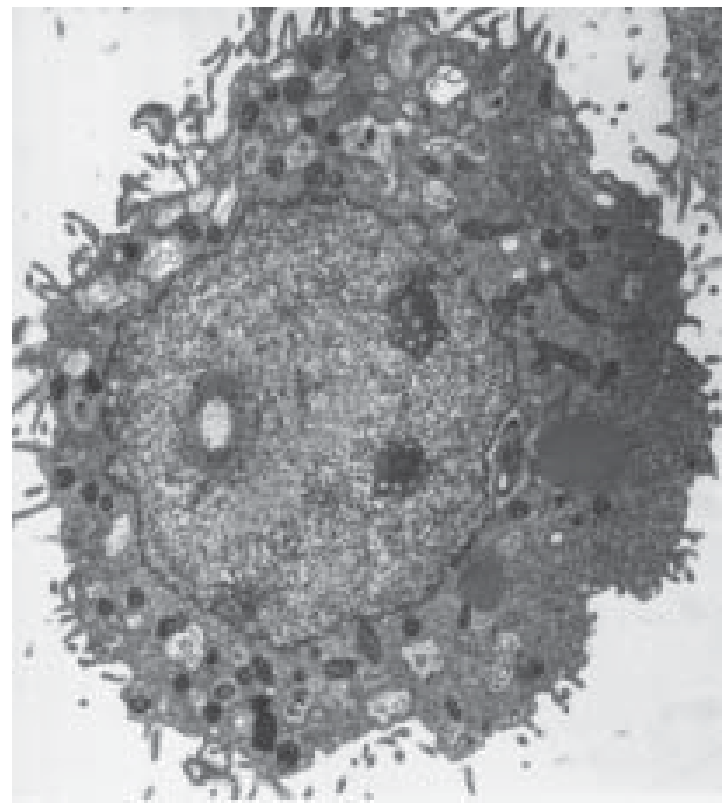

Figura 2. Micrografía electrónica de célula epitelial mamaria diferenciada HC11 IM 9.000X.

Los gráficos que se presentan a continuación permiten evaluar la variación de las fracciones volumétricas de cada uno de los diferentes componentes celulares en medida que acontece diferenciación en este sistema biológico, estableciéndose nuevos marcadores del mecanismo, producto de la estimulación lactogénica. La Figura 3 describe el resultado de la evaluación morfométrica, determinándose las fracciones volumétricas del núcleo y del nucleolo pertenecientes tanto a células normales como diferenciadas, evidenciándose con claridad marcada diferencia cuantitativa entre ellos.

En este mismo contexto, la Figura 4 describe las fracciones volumétricas correspondientes a los distintos tipos de cromatina evaluados mediante las técnicas morfométricas tanto en $\mathrm{HC} 11 \mathrm{GM}$ como en HC11 IM, observándose igualmente disparidad relativa a la estructura en cuestión.

Finalmente, en la Tabla I se describe con precisión la acentuada diferencia expresada en micrones cuadrados encontrada al evaluar el área perteneciente tanto de células normales como diferenciadas.

\section{DISCUSIÓN}

De acuerdo a los resultados obtenidos derivados de la cuantificación morfométrica, considerando específicamente el valor de la fracción volumétrica del núcleo, se observa con claridad una marcada disminución del volumen nuclear observado en la célula diferenciada con respecto a la célula normal y proliferante, hallazgo que coincide plenamente con lo demostrado en relación a la morfología de células en proceso de diferenciación (8).

En este mismo sentido, pareciera lógico argumentar que la reducción en el volumen nuclear como la acentuada disminución en 13 micrones cuadrados del área encontrada al comparar la masa citoplasmática de las células HC11 GM y IM sea una respuesta a las estimulaciones de las hormonas lactogénicas, considerando su funcionalidad anabólica. En este contexto, fue demostrado el rol promotor de dexametasona en diferenciación celular, y el hecho que posea la misma constitución química esteroidal característica de estrógenos, los cuales probadamente inducen muchas actividades enzimáticas involucradas en la síntesis de DNA, como también un aumento en la transcripción de genes y subsecuente síntesis proteica, apunta a favor de que ambos tipos hormonales posean acción semejante en la promoción de la diferenciación celular (9).

Del mismo modo, es tentador argumentar que esta diferencia de masa citoplasmática se deba a

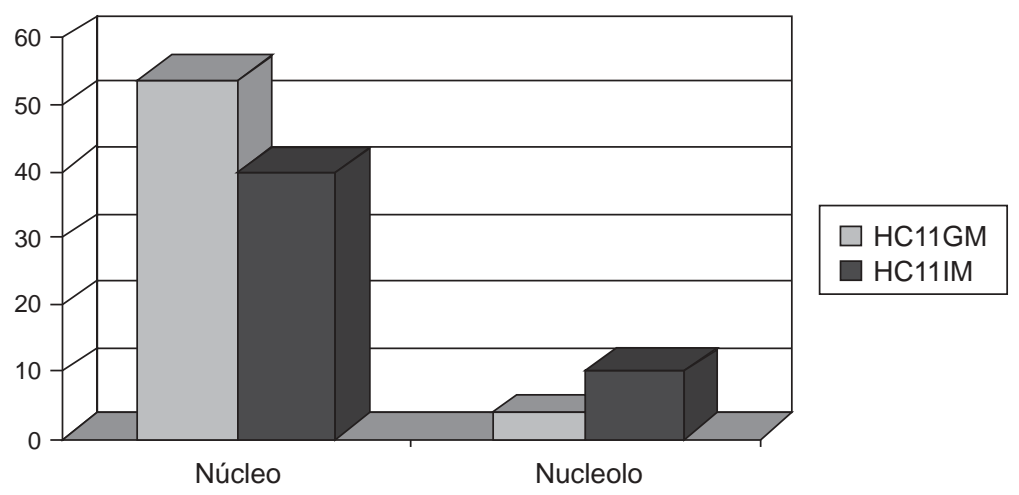

Figura 3. Fracciones volumétricas (\%) correspondientes a componentes de células mamarias normales-proliferantes y diferenciadas. 
Figura 4. Fracciones volumétricas correspondientes a tipos de cromatina cuantificada en células mamarias normales-proliferantes y diferenciadas

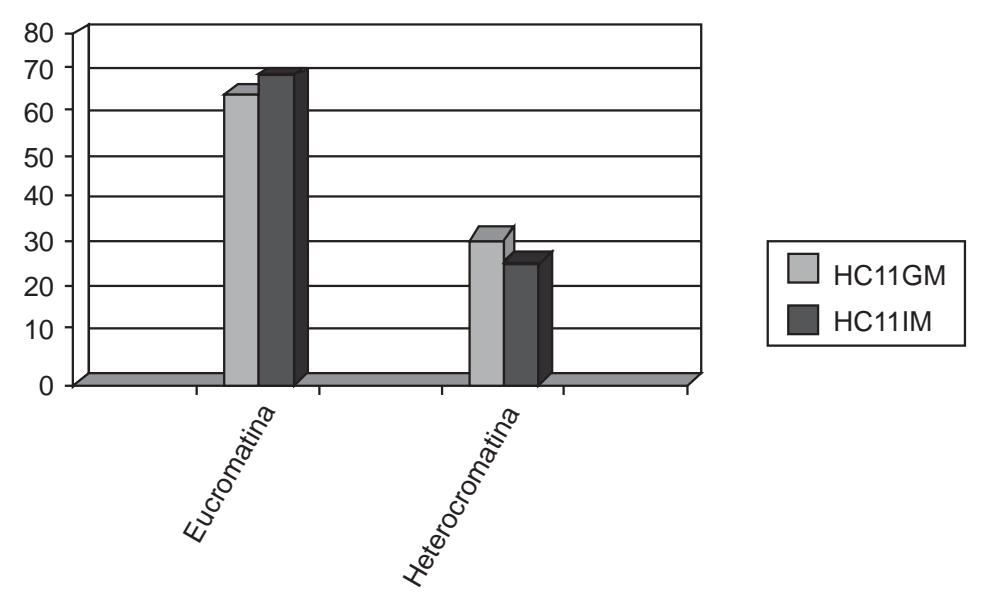

Tabla I

\section{ÁREA EXPRESADA EN MICRONES CUADRADOS CORRESPONDIENTE A CÉLULAS MAMARIAS NORMALES Y DIFERENCIADAS}

\begin{tabular}{lc}
\hline$H C 11$ GM & $H C 11$ IM \\
\hline 167 micrones $^{2}$ & 154 micrones $^{2}$ \\
\hline
\end{tabular}

un proceso de acondicionamiento de componentes celulares destinados específicamente a la síntesis tanto de $\beta$ caseína, la primera principal proteína de la secreción láctea, como de filamentos intermediarios de citoqueratina, proteínas tubulares, ambos generados por este tipo celular diferenciado, exclusivamente (10).

Del mismo modo, de acuerdo al análisis de los valores encontrados tanto para eu como heterocromatina en $\mathrm{HC} 11$ IM permite concluir claramente que este tipo celular ya diferenciado presentan una tasa de síntesis y secreción proteica aumentada con respecto a la exhibida por la célula normal y proliferante. En este mismo sentido, la cuantificación relativa a la fracción volumétrica del nucléolo, triplicada en HC11 IM argumenta a favor de un notable incremento en la biosíntesis ribosomal.

Al respecto, Hynes et al en 1992 (7), demostró que las células HC11 en crecimiento sintetizan y secretan las glicoproteínas laminina y tenascina, pudiendo ser visualizadas tanto en el citoplasma en forma de vacuolas como en el espacio extracelular como fibrillas finas.

\section{BIBLIOGRAFÍA}

1. Bal De Kier E, Adam A. Transformación celular y mecanismos de sobrevida regulados por la GTPasa Ral. Medicina 2001; 61: 658-63.

2. Guyette WA, Matusik RJ, Rosen JM. Prolactinmediated transcriptional and post-transcriptional control of casein gene expression. Cell 1979; 17: 101323.

3. Fawcett DW. Tratado de Histología $11^{\underline{a}}$ ed. Interamericana-Mc Graw-Hill, 1987; 345-70.

4. Doppler, W, Groner B, Ball RK. Prolactin and glucocorticoid hormones synergistically induce expression of transfected rat beta-casein gene promoter constructs in a mammary epithelial cell line. Proc Natl Acad Sci USA 1989; 86: 104-8.

5. Carpenter G, Cohen S. Epidermal Growth Factor. Biol Chem 1990; 265: 7709-12.

6. Taverna D, Groner B, Hynes NE. Epidermal growth factor receptor, platelet-derived growth factor receptor, and c-erbB-2 receptor activation all promote growth but have distinctive effects upon mouse mammary epithelial cell differentiation. Cell Growth \& Differentiation 1991; 2: 145-54.

7. Hynes NE, Taverna D, Cella N, Chammas R. The effect of the extracelular matrix upon $\mathrm{HC} 11$ mammary epithelial cell differentiation. Ciencia e Cultura 1992; 44: 253-6.

8. Junqueira LCU, Salles LMM. Ultraestrutura e funçao celular. Rio de Janeiro: Guanabara-Koogan 1975; 40 7.

8. Chaudhuri PK, Walker MJ, Beattie CW, Das Gupta TK. Endocrine correlates of human malignant melanoma. J Surg Res 1979; 26: 214-9.

9. Cornejo R, Joazeiro P, Chammas R, Montes G, Caldini E. Morfometría de la diferenciación de células mamarias en cultivo. Rev Chil Anat 1995; 13: 33-41.

10. Lodish H, Berk A, Zipursky S, Matsudaira P, Baltimore D, Darnell J. Biología Celular y Molecular. $4^{\mathrm{a}}$ ed. Madrid, Editorial Médica Panamericana, 2003; 320-24. 